\title{
Effects of the Internet use on Wellbeing and Academic Attainment of Students Starting University
}

\author{
Hasah Alheneidi, PhD, Andrew P Smith, PhD* \\ School of Psychology, Cardiff University, 63 Park Place, Cardiff, CF10 3AS, UK \\ *Corresponding Author: Andrew P Smith, PhD, School of Psychology, Cardiff University, 63 Park \\ Place, Cardiff, CF10 3AS, UK

\begin{abstract}
Previous research suggests that internet addiction, or problematic internet use, reduces the wellbeing and academic attainment of university students. A major problem with much of the previous research is that the studies have not controlled for established predictors of wellbeing and attainment. When this has been done, the effects of internet use on wellbeing have no longer been significant, although a negative effect of internet use on attainment still remained. This topic was examined in the present study which also controlled for information overload. 179 first year university students completed the internet addiction test, the information overload scale and the student wellbeing process questionnaire. Correlational analyses showed that internet addiction was associated with negative wellbeing and negatively associated with positive wellbeing. Numerically, internet addiction scores were associated with poorer attainment but these effects were not significant, possibly reflecting the sample size. The associations between internet addiction and wellbeing were not significant when established predictors of wellbeing (positive personality, social support, exposure to stressors and negative coping) were covaried. Further research is needed to extend these findings using longitudinal designs, other samples (e.g. high users of the internet, workers) and assessment of type of internet use.
\end{abstract}

Key words: Internet use, internet addiction, academic attainment, wellbeing.

\section{INTRODUCTION}

The aim of the present study was to examine associations between internet use, wellbeing and academic attainment in students starting university in the UK. The wellbeing process model was used as a framework for reviewing previous literature on the effects of internet use, and the key features of the model are described in the next section.

\subsection{The Wellbeing Process}

The "wellbeing process model" provides a holistic theoretical framework and has led to a questionnaire (the WPQ) that has been widely used (Williams \& Smith, 2012, 2016, 2018a, 2018b; Williams, Pendlebury \& Smith, 2017; Williams, Thomas \& Smith, 2017; Smith, 2018;). A version of the Wellbeing Process Questionnaire has also been used in research with university students (Williams, Pendlebury, Thomas \& Smith, 2017; Smith, 2019; Bowen \& Smith, 2019; Howells \& Smith, 2019; Omosehin \& Smith, 2019a,b,c; Smith \& Firman, 2019; Smith \& Firman, 2020; Smith \& Idzayar, 2020). The theoretical approach was based on the Demands-Resources-Individual Effects (DRIVE) model (Mark \& Smith, 2008) which examined associations between job characteristics, perceived stress, coping styles and anxiety and depression. Later versions of the DRIVE model (Smith, et al. 2011; Wadsworth, et al., 2010) also included positive variables such as optimism, selfefficacy, self-esteem,life satisfaction, positive affect and happiness, life satisfaction, positive affect and happiness are key concepts in many models of subjective wellbeing.

This Student WPQ has good reliablility and validity. It has been used in many cross-sectional studies and also longitudinal research which can inform about causal relationships (Galvin, 2016). Similar results have been obtained using other questionnaires based on the wellbeing process model (e.g. the Smith Wellbeing Questionnaire, SWELL, Smith \& Smith, 2017a, 2017b, 2017c; Fan \& Smith, 2017a, 2017b, 2018; Alharbi \&Smith, 2019). As the model developed many variables needed to be included in the questionnaire and inclusion of all of these scales led to a very long survey that was not very 
acceptable to the participants. To overcome this problem, short scales were developed and these were significantly correlated with the measuress from which they were derived.

\subsection{Internet Addiction}

Research on internet use started in the mid-1990s. With the evolving research on internet and information technology there has been no single approved term that defines problematic internet use. Researchers have used many different terms to describe the topic including "Pathological Internet Use" (Davis, 2001; Shapira, Goldsmith, Keck, Khosla, \& McElroy, 2000; Young, 1998), "Problematic Internet Use" (Caplan, 2002; Davis, Flett, \& Besser, 2002), "Maladaptive Internet Use" (Davis et al., 2002; Kubey, Lavin, \& Barrows, 2001), "Excessive Internet Use" (Beard, 2002), "Internet Dependence" (Scherer, 1997; Young, 1996), "Internet Behavior Dependence" (Hall \& Parsons, 2001), "Internet Over-use" (Whang, Lee, \& Chang, 2003), "Internet related disorder" (Pratarelli \& Browne, 2002) and "Misuse of the Internet" (Greenfield \& Davis, 2002). The different terms reflect the uncontrolled use of the internet and neglect of other things due to this. Two major models were established to conceptualise problematic internet use symptoms and are described below.

\subsection{Impulse Control Disorder Model.}

Young (1996) proposed the impulse control disorder model, which corresponds with the classification of pathological gambling in DSM-IV as one of the impulse control disorders. She defined internet addiction as the excessive use and dependence on the internet which causes life impairment. She also stated that individuals with problematic internet use showed similar symptoms to pathological gamblers, as well as individuals who are dependent on drugs and alcohol. As a type of impulsecontrol disorder, Young (1996) conceptualised and developed the Diagnostic Questionnaire for Internet addiction, based on pathological gambling measures in the DSM-IV. Common symptoms of the disorder include: unsuccessful attempts to stop or cut down, preoccupation with internet activity, strong need to connect online, feelings of loss of control, tolerance and withdrawal symptoms, and neglect of social and academic obligations. Other researchers supported Young's model and hypothesised that problematic internet use is a form of obsessive-compulsive disorder (OCD). Young presented this as repetitive pathological behaviours of online activities which closely resemble some of the common symptoms of OCD, including behaviours that are time consuming and uncontrollable, as well as experiencing occupational and social difficulties (Shapira et al., 2000). However, Shapira et al.'s (2003) results on college students suggest that problematic internet use should only be classified as an impulse control disorder. Clinical cases and reports have supported the model based on the listed diagnostic criteria in the DSM-IV. The adoption and application of the model is easy.

\subsection{Cognitive-Behavioural Model.}

Davis (2001, 2002) proposed the Cognitive-Behavioral model for problematic internet use, highlighting the motivating psychological characteristics and personal cognitions behind the pathological internet use (PIU). He stated that each abnormal and intensive behavior was caused by the individual's cognitions and PIU was due to pre-existing psychological problems such as social anxiety, depression, low self-esteem or maladaptive cognitions. Davis classified problematic internet users into two groups. The first, Generalized Problematic Internet Users (GPIU), are dependent on the internet itself, without being addicted to a specific internet activity. They also show more internet addiction symptoms if these are associated with other problems such as low work performance. Davis explained pathological internet use as being due to the "individual social context" including a lack of social support, social shyness, and isolation.The other group is the Specified Problematic Internet Users (SPIU) who are attracted to a particular internet activity such as gambling or viewing social media content, and who may stop their internet dependency if they find an alternative provider for the same content. Holden (2001) supported the idea that most internet addictive activities were similar to the offline addictive activities such as shopping, gambling and pornography. He added that the internet combined all things that people can get addicted to. Holmes' (1997) findings supported Davis' model which suggested that internet dependency reflected psychological issues. Davis' model was also supported by the earlier results of Petrie and Gunn (1998), who found that internet addiction was negatively correlated to positivity and extroversion but positively correlated with depression. They concluded that internet addicts were probably introverted and depressed. 


\subsection{Social Network Addiction}

The use of Social Network Services (SNS) has increased rapidly in past years and has become a part of millions of users' daily lives to share and communicate with others. The development of rapid connection technology, the use of smartphones and permanent online connection has enabled individuals to communicate constantly with others all of the time (Choi \& Lim, 2016). The use of smartphone-based SNS is preferable for many individuals (Kwon, M., Kim, D.J., Cho, H. \& Yang, 2013) and the advantages of smartphone-based SNS lie in the ability to connect with no time or place limit, feeling related, and increased life satisfaction if the connection is controlled (Ellison, Steinfield, \& Lampe, 2007; Valenzuela, Park, \& Kee, 2009). However, ubiquitous SNS connectivity can have negative consequences psychologically and from an information perspective. SNS can result in increasing information overload, communication overload and social fatigue (Eppler \& Mengis, 2004; Jones et al., 2004; Lee, Son, \& Kim, 2016; Soto-Acosta, Molina-Castillo, Lopez-Nicolas, \& ColomoPalacios, 2014).The next section discusses literature on internet use and wellbeing using the Wellbeing Process as a framework for the review.

\subsection{Internet Addiction and Wellbeing}

In a literature review covering the period 2000-2017 (Alheneidi, 2019) PubMed and PsycINFO databases were searched for peer-reviewed articles published in English that addressed the association between internet addiction and wellbeing in adults. Studies were selected based on their relation to the association of wellbeing, mental health and internet addiction. Studies on adolescents were excluded, as were studies on online gaming addiction disorder studies which were classified as a separate disorder. Qualitative, quantitative and case studies were considered. The following search terms were used: "compulsive internet use," "internet addiction," "problematic internet use," "mental health," and "wellbeing". After duplicates were excluded there were 146 results for internet addiction and wellbeing. The first author read all abstracts and full text of relevant articles. In the conducted review a total of 35 empirical studies were identified. The majority of studies were cross-sectional $(n=29)$, four were longitudinal studies, one was qualitative, and one was an experimental study. Studies were classified into four main themes and sub-themes. The main themes were the association between internet addiction and positive and negative outcomes, internet addiction and predictors of wellbeing, internet addiction and individual effects, and internet addiction and appraisals. In the reviewed studies, the sample sizes varied from 101 to 23,533 adults. Two search engines were used, PubMed and PsychInfo, and the search terms used are described below.

PubMed.

- Search (((("internet addiction"[Title/Abstract]) OR "compulsive internet us*"[Title/Abstract]) OR "problematic internet us*"[Title/Abstract]) AND "mental health"[Title/Abstract]) Filters: English language, Publication date from 2000/01/01 to 2017/12/31 results 61

- $\quad(((($ internet addiction"[Title/Abstract]) OR "compulsive internet us*"[Title/Abstract]) OR "problematic internet us*"[Title/Abstract]) AND "wellbeing"[Title/Abstract]) Filters: English language, Publication date from 2000/01/01 to 2017/12/31 results 16 PsychINFO.

- Compulsive internet us* or problematic internet us* or internet addiction AND Wellbeing or wellbeing or mental health (peer reviewed) publication date 2000-2017 results 94

- Compulsive internet us* or problematic internet us* or internet addiction AND Academic performance (peer reviewed) publication date 2000-2017 results 30

The results of these previous studies are summarised below.

\subsection{Internet Addiction and Wellbeing.}

Most wellbeing and internet addiction studies have used university student samples and produced results which show that problematic internet use influences negative psychological wellbeing (Alavi et al., 2011; Cardak, 2013; Casale et al., 2015). Akin (2012) confirmed that internet addiction was associated with lower subjective vitality and happiness scores. Chen (2012) and Muusses et al.'s (2014) longitudinal studies revealed that increased PIU lowers wellbeing, through an increase in stress, depression and loneliness. Low life satisfaction influenced PIU (Senol-Durak \& Durak, 2011), however Kutty and Sreeramareddy's (2014) findings conflicted with these previous results, which suggests that compulsive internet use influences general health. Senol-Durak and Durak (2011) 
carried out a similar cross-sectional study using the same GHQ and Facebook Addiction Scale measures and confirmed the association between insomnia, anxiety and severe depression with Facebook addiction. The next section considers a specific outcome, namely, depression.

\subsection{Internet Addiction and Depression}

The review of the association between internet addiction and depression showed that findings from Gedam et al. (2011), Hirao (2015), and Iacovelli and Valenti (2009) supported the idea that internet addicts have more depressive symptoms compared to non-addicts. Internet addicts reported higher scores of depressive moods and used the internet to escape from their depression (Whang et al., 2003). A cross- cultural study also found that Chinese internet addicts scored the highest on depressive symptoms (Tang et al., 2016). The main problems with the literature were the failure to use appropriate models of wellbeing and to control for other predictors. The next section reviews studies on internet addiction and predictors of wellbeing.

\subsection{Internet Addiction and Social Interaction}

A number of studies have shown that problematic use of the internet is associated with issues relating to social interaction. For example, Naseri, Mohamadi, Sayehmiri, \& Azizpoor (2015) found that there were significant negative correlations between internet addiction and perceived social support, as well as family support. These results were also obtained by Quinones and Kakabadse (2015). Studies on these topics have utilised a range of different methodologies: cross-sectional, qualitative and experimental. They have all studied the association between internet addiction and social support and loneliness, using samples from different cultures, and confirmed the association of PIU and problematic Facebook use with loneliness, social anxiety, lower family functioning, low social skills and low self-esteem.

\subsection{Internet use and Personality}

A number of studies have examined associations between personality traits and internet use (Laconi et al., 2018; Tsai et al.,2009; Marino et al., 2016; Yan et al., 2014; Andreassen, Torsheim, Brunborg, \& Pallesen, 2012). The findings confirmed the strong association with personality disorder clusters B and $\mathrm{C}$, neuroticism traits, immature defensive style, psychoticism characteristics, introversion and low self-esteem. The studies featured large samples from different cultures, used different personality scales and confirmed the positive association between personality disorders and internet addiction.

The review on problematic internet use and wellbeing suggested an association between internet use and wellbeing. However, internet use was also associated with the predictors of wellbeing, and there is a need to investigate whether the association between internet use and wellbeing outcomes remains significant when the established predictors of wellbeing are controlled. Recent research (Smith \& Idadyar, 2019) has found that distraction from the internet does not influence wellbeing when established predictors are controlled for. The present study continued this research using an established measure of internet addiction.

\subsection{Internet use and Academic Attainment}

Skues, Williams, Oldmeadow, and Wise (2016) examined the effects of loneliness, boredom and distress tolerance on PIU, in a sample of 169 undergraduate university students. The association between academic performance and PIU was also measured. The results indicated that boredom was significantly associated with PIU and played a moderator role in a model that included distress tolerance and loneliness. Low academic performance was correlated with problematic internet use. Min-Pei et al. (2011) conducted a study on a sample of 3,616 Taiwanese university students and the results indicated that internet addicts have lower academic performance satisfaction. A recent study by Smith \& Izadyar (2019) found that distraction from the internet was associated with lower GPA scores. This effect remained significant when established predictors of academic attainment were included in the analyses.

The current study aimed to identify the relationships between internet addiction, wellbeing and academic attainment. The Student WPQ includes established predictors of wellbeing, namely social support, positive personality,exposure to stressors, and coping strategies which can be statistically controlled when analysing the effects of problematic internet use. Actual GPA scores (examination and coursework scores) were the attainment measure and predictors of these were also included in the 
analyses. Excessive internet use can be one of the causes of information overload. A questionnaire measuring information overload (Misra \& Stokols, 2012) was, therefore, used in the present study to control for other sources which may contribute to the overall overload.

\section{METHOD}

\subsection{Participants}

Based on Cohen's d calculations and the lack of previous data from similar studies, a sample size of 100 was needed to identify medium size effects. One hundred and seventy-nine first year psychology undergraduate students participated in the study as part of their course requirements. The majority of the sample population $(91 \%)$ were females. The age range was $18-50$ years; $89.9 \%$ were $18-21$ years old. Course and exam scores were collected at the end of the semester using students' ID numbers.

\subsection{The Survey}

Questionnaires were completed electronically in a computer laboratory at the beginning of the academic year. Consent with the key features of voluntary participation, freedom to withdraw, anonymous databases, instructions and debrief forms were provided at the start and the end of the study. The ethics committee of Cardiff University's School of Psychology approved the study.

\subsection{Measuring Instruments}

The survey included the Internet Addiction Test (IAT), Perceived Information Overload Scale (IOS) and the Student Wellbeing Process Questionnaire (WPQ). Attainment scores (examination and coursework marks) were obtained at the end of the first semester.

\subsubsection{Internet Addiction Test (IAT)}

The IAT was developed by Young (1998) and consists of 20 items that examine the use of the internet for non-academic or non-job purposes during the last month. Young developed the measure based on DSM-IV criteria of pathological gambling, the criteria aiming to identify a type of behavioural addiction. The test is a widely used reliable and valid measure. The participant answers the questions using Likert scales $(0=$ not applicable and $5=$ always $)$. For example, 'How often do you find that you stay online longer than you intended?' and 'How often do you neglect household chores to spend more time online?' All of the questions are provided below. The sum of scores demonstrate three types of internet users, reflecting their dependency on the internet, these are: controlled internet user, problematic internet user, and internet addicts.

- Scores from 31-49 reflect an average online user who controls his/her online activity.

- 50-79 points reflect an individual experiencing occasional or frequent problematic internet use that might interfere with normal life flow.

- 80-100 points reflect internet usage that is causing significant problems in an individual's life.

\subsubsection{Internet Addiction Test Questions}

1. How often do you find that you stay online longer than you intended?

2. How often do you neglect household chores to spend more time online?

3. How often do you prefer the excitement of the Internet to intimacy with your partner?

4. How often do you form new relationships with fellow online users?

5. How often do others in your life complain to you about the amount of time you spend online?

6. How often do your grades or school work suffer because of the amount of time you spend online?

7. How often do you check your email before something else that you need to do?

8. How often does your job performance or productivity suffer because of the Internet?

9. How often do you become defensive or secretive when anyone asks you what you do online?

10. How often do you block out disturbing thoughts about your life with soothing thoughts of the Internet?

11. How often do you find yourself anticipating when you will go online again? 
12. How often do you fear that life without the Internet would be boring, empty, and joyless?

13. How often do you snap, yell, or act annoyed if someone bothers you while you are online?

14. How often do you lose sleep due to late-night log-ins?

15. How often do you feel preoccupied with the Internet when off-line, or fantasize about being online?

16. How often do you find yourself saying "just a few more minutes" when online?

17. How often do you try to cut down the amount of time you spend online and fail?

18. How often do you try to hide how long you've been online?

19. How often do you choose to spend more time online over going out with others?

20. How often do you feel depressed, moody, or nervous when you are off-line, which goes away once you are back online?

\subsubsection{Perceived Information Overload Scale (Misra \& Stokols, 2012)}

The Perceived Information Overload Scale $(\alpha=.86)$ is a 16-item scale that consists of two subscales. The first part consists of nine items that explore the user's experience of information overload from cyber-based sources in the previous month, through a Likert scale of 5-points $(0=$ never and $4=$ very often). Information users were asked about how often they felt overwhelmed to answer emails/ instant messages quickly; how often they felt that they had too many messages/emails or any social network notifications. The second part of the scale consisted of seven items surveying participant's experience of the environment, or place, based on information overload in the last month. The questions included: workplace demands exceeding the user's ability to work, as well as a noisy and distracting work environment; full scale items are provided below. The items were totalled to produce a total cyber-based information overload score and place-based information overload score. The sum of the two scores reflects the total perceived information overload score (Misra \& Stokols, 2012). Although information overload is a stress indicator, the findings of Misra and Stokols (2012) indicate that the Perceived Information Overload Scale score and the Perceived Stress Scale score were not overlapping, which suggested that cyber-based and place-based information overload scales measured different concepts than perceived stress.

\subsubsection{Information Overload Questions}

1. In the last month how often you felt overwhelmed with the email messages you received?

2. In the last month, how often have you forgotten to respond to important email messages?

3. In the last month how often you felt pressured to respond to email messages quickly?

4. In the last month, how often have you received more cell phone calls than you can handle?

5. In the last month, how often have you felt that you receive more email attachments than you can handle?

6. In the last month, how often have you felt that you have had to spend much time maintaining the various information and communication devices you own (e.g., laptops, desktop computers, personal digital assistants)?

7. In the last month, how often have you felt pressured to manage several information and communication inputs at the same time?

8. In the last month, how often have you felt that you have too many messages (e.g., wall postings, event notifications, personal messages, status updates, and applications) on your Facebook or Myspace page to deal with?

9. In the last month, how often have you felt that you have receive more instant messages that you can handle?

10. In the last month, how often have you felt that your work activities leave you too little for recreational activities?

11. In the last month, how often have you felt that your work demands make you less sensitive to the needs of others? 
12. In the last month, how often have you felt hassled by your commute to work?

13. In the last month, how often have you felt that you have too many demands in your home to be able to handle comfortably?

14. In the last month, how often have you felt that the demands on you in your workplace exceed your capacity to deal with them?

15. In the last month, how often have you felt that your home environment is too noisy?

16. In the last month, how often have you felt that your work environment is too noisy?

\subsubsection{Measuring Wellbeing: The Wellbeing Process Questionnaire (WPQ)}

The Wellbeing Process Questionnaire (WPQ) was developed to study wellbeing in workers (Williams \& Smith, 2012), and students (Williams et al., 2017). The concepts measured were based on singleitem questions designed to correlate highly with longer versions of the scales (Williams, 2014). This resulted in a valid and reliable short questionnaire for investigating wellbeing in circumstances that require brief scales like the workplace (Williams \& Smith, 2016). The nature of wellbeing suggested that one has to consider multiple variables. Using short items to measure them is ideal, and saves time, cost and effort. The wellbeing outcome score can be calculated using the combined effects of positive wellbeing (e.g., life satisfaction and happiness) and negative wellbeing (e.g., depression, anxiety, and stress; Williams, 2012). The WPQ can be combined with other multi-item scales and the established predictors of control. The WPQ is flexible and can be customised for use with specific populations and Williams, Smith and co-workers have developed a bank of questions for use with a variety of groups. The result of using the WPQ with different samples such as students (Williams et al., 2017), workers (Williams \& Smith, 2013, 2016, 2018) nurses (Williams et al., 2017), university staff (Williams et al., 2017), police officers (Nelson \& Smith, 2016), and train workers (Fan \& Smith, 2017) have revealed that the wellbeing outcomes are consistently predicted by the established factors and the short questionnaire often has the same predictive validity as multi-item scales.

\subsubsection{The Student $W P Q$}

The Student WPQ is a multidimensional scale of wellbeing which includes a measure of stressors based on students' circumstances and factors from the Inventory of College Students' Recent Life Experiences (ICSRLE), such as development challenges, social mistreatment and time pressures (Kohn et al., 1990). The student WPQ version also measures other wellbeing predictors based on the DRIVE model: negative coping, social support, and positive personality (self-efficacy, self-esteem and optimism). Participants answered the WPQ questions using a 10 -point scale $(0=$ not at all, $10=$ extremely). The items covered the 7 items of students' life demands based on the ICSRLE factors, questions measuring the student's social support, personality, positive and negative outcomes, coping style, life satisfaction, life stress, physical fatigue, and mental fatigue (Williams, 2014). The WPQ scale provides a clear result of positive and negative outcomes and predictors. Wellbeing predictors are measured in single items and can be calculated individually. Negative wellbeing was the sum of the scores of depression, negative affect and anxiety. Negative appraisal was the sum of the scores of life stress, physical fatigue and mental fatigue. Positive wellbeing was the sum of scores of positive effects, and positive appraisal was represented by the life satisfaction score. The individual questions are shown below.

\section{The Student WPQ: Student Stressors}

Please consider the following elements of student life and indicate overall to what extent they have been a part of your life over the past 6 months. Remember to use the examples as guidance rather than trying to consider each of them specifically:

Challenges to your development (e.g. important decisions about your education and future career, dissatisfaction with your written or mathematical ability, struggling to meet your own or others' academic standards).

Not at all part of my life 12345678910 Very much part of my life

Time pressures (e.g. too many things to do at once, interruptions of your school work, a lot of responsibilities).

Not at all part of my life 12345678910 Very much part of my life 
Academic Dissatisfaction (e.g. disliking your studies, finding courses uninteresting, dissatisfaction with school).

Not at all part of my life 12345678910 Very much part of my life

Romantic Problems (e.g. decisions about intimate relationships, conflicts with boyfriends'/girlfriends' family, conflicts with boyfriend/girlfriend).

Not at all part of my life 12345678910 Very much part of my life

Societal Annoyances (e.g. getting ripped off or cheated in the purchase of services, social conflicts over smoking, disliking fellow students).

Not at all part of my life 12345678910 Very much part of my life

Social Mistreatment (e.g. social rejection, loneliness, being taken advantage of).

Not at all part of my life 12345678910 Very much part of my life

Friendship problems (e.g. conflicts with friends, being let down or disappointed by friends, having your trust betrayed by friends).

Not at all part of my life 12345678910 Very much part of my life

\section{Social Support}

Please state how much you agree or disagree with the following statements:

Tangible

There is a person or people in my life who would provide tangible support for me when I need it (for example: money for tuition or books, use of their car, furniture for a new apartment).

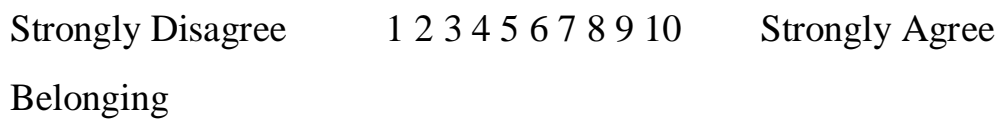

There is a person or people in my life who would provide me with a sense of belonging (for example: I could find someone to go to a movie with me, I often get invited to do things with other people, I regularly hang out with friends).

Strongly Disagree $\quad 12345678910 \quad$ Strongly Agree

Emotional

There is a person or people in my life with whom I would feel perfectly comfortable discussing any problems I might have (for example: difficulties with my social life, getting along with my parents, sexual problems).

\section{Strongly Disagree $\quad 12345678910 \quad$ Strongly Agree}

Positive Personality:

In general, I feel optimistic about the future (For example: I usually expect the best, I expect more good things to happen to me than bad, It's easy for me to relax)

I am confident in my ability to solve problems that I might face in life (For example: I can usually handle whatever comes my way, If I try hard enough I can overcome difficult problems, I can stick to my aims and accomplish my goals)

Overall, I feel that I have positive self-esteem (For example: On the whole I am satisfied with myself, I am able to do things as well as most other people, I feel that I am a person of worth)

\section{Negative Coping:}

When I find myself in stressful situations, I blame myself (e.g. I criticize or lecture myself, I realise I brought the problem on myself). 
When I find myself in stressful situations, I wish for things to improve (e.g. I hope a miracle will happen, I wish I could change things about myself or circumstances, I daydream about a better situation).

When I find myself in stressful situations, I try to avoid the problem (e.g. I keep things to myself, I go on as if nothing has happened, I try to make myself feel better by eating/drinking/smoking).

\section{Positive Appraisal}

Overall, I feel that I am satisfied with my life (For example: In most ways my life is close to my ideal, so far I have gotten the important things I want in life)

\section{Negative Appraisal}

Overall, how stressful is your life?

Overall, how often do you feel physically fatigued?

Overall, how often do you feel mentally fatigued?

\section{$\underline{\text { Positive outcomes }}$}

Thinking about myself and how I normally feel, in general, I mostly experience positive feelings (For example: I feel alert, inspired, determined, attentive)

\section{Negative Outcomes}

Thinking about myself and how I normally feel, in general, I mostly experience negative feelings (For example: I feel upset, hostile, ashamed, nervous)

On a scale of one to ten, how anxious would you say you are in general? (e.g. feeling tense or 'wound up', unable to relax, feelings of worry or panic)

How depressed would you say you are in general? (e.g. feeling 'down', no longer looking forward to things or enjoying things that you used to)

\subsection{Analysis Strategy}

SPSS 25.00 was used to conduct all statistical analyses. The reliability of the scales was tested by Cronbach alpha coefficients. Pearson univariate correlations were conducted to evaluate the strength of the relationships among internet addiction, information overload, wellbeing total outcome scores. The internet addiction scores were dichotomised based on IAT scoring to compare those with controlled internetuse and those with problematic internet use.

\section{RESUlts}

\subsection{Correlations}

The total internet addiction score (IA) was significantly correlated with negative wellbeing (sum of outcomes and appraisals: $\mathrm{r}=0.24 \mathrm{p}<0.001$ ) and positive wellbeing (sum of outcomes and appraisals: $\mathrm{r}=-0.28 \mathrm{p}<0.001)$. The correlations between IA and academic attainment scores were in the predicted direction (negative correlations) but were not statistically significant. IA was correlated with the information overload media $(r=0.26 \mathrm{p}<0.001)$ and information overload non-media $(r=0.22 \mathrm{p}$ $<0.005)$ scores. IA was also significant associated with wellbeing predictors (negative coping: $\mathrm{r}=$ $0.33 p<0.001$; social support: $r=-0.19 p<0.05$; positive personality: $r=-.022 p<0.005$ ).

The next set of analyses controlled for established predictors and examined whether IA was still associated with the wellbeing outcomes.

\subsection{Regression Analyses}

The Positive outcome score was the dependent variable in the first regression. The results of the regression are shown in Table 1. The significant predictors were social support and positive personality. When the established predictors were included in the regression, the effect of internet addiction was no longer present. 
Table1. Positive Outcome Regressions

\begin{tabular}{|c|c|c|c|c|c|c|}
\hline \multicolumn{7}{|c|}{ Coefficients $^{\mathrm{a}}$} \\
\hline \multicolumn{2}{|c|}{ Model } & \multicolumn{2}{|c|}{ Unstandardized Coefficients } & \multirow{2}{*}{$\begin{array}{l}\text { Standardized } \\
\text { Coefficients } \\
\text { Beta }\end{array}$} & \multirow[t]{2}{*}{$\mathrm{t}$} & \multirow[t]{2}{*}{ Sig. } \\
\hline & & B & Std. Error & & & \\
\hline \multirow[t]{7}{*}{1} & (Constant) & 5.125 & 1.908 & & 2.686 & .008 \\
\hline & Stressors & -.031 & .019 & -.096 & -1.624 & .106 \\
\hline & Social support & .158 & .045 & .185 & 3.523 & .001 \\
\hline & Negative Coping & -.011 & .043 & -.014 & -.243 & .808 \\
\hline & Positive Personality & .315 & .030 & .594 & 10.629 & .000 \\
\hline & Non- media IO & -.060 & .033 & -.098 & -1.839 & .068 \\
\hline & IA & -.024 & .018 & -.072 & -1.339 & .182 \\
\hline
\end{tabular}

In the negative wellbeing regression the established predictors had their usual significant effects. Internet addiction was no longer significant when the established predictors were included.

Table2. Negative wellbeing regression

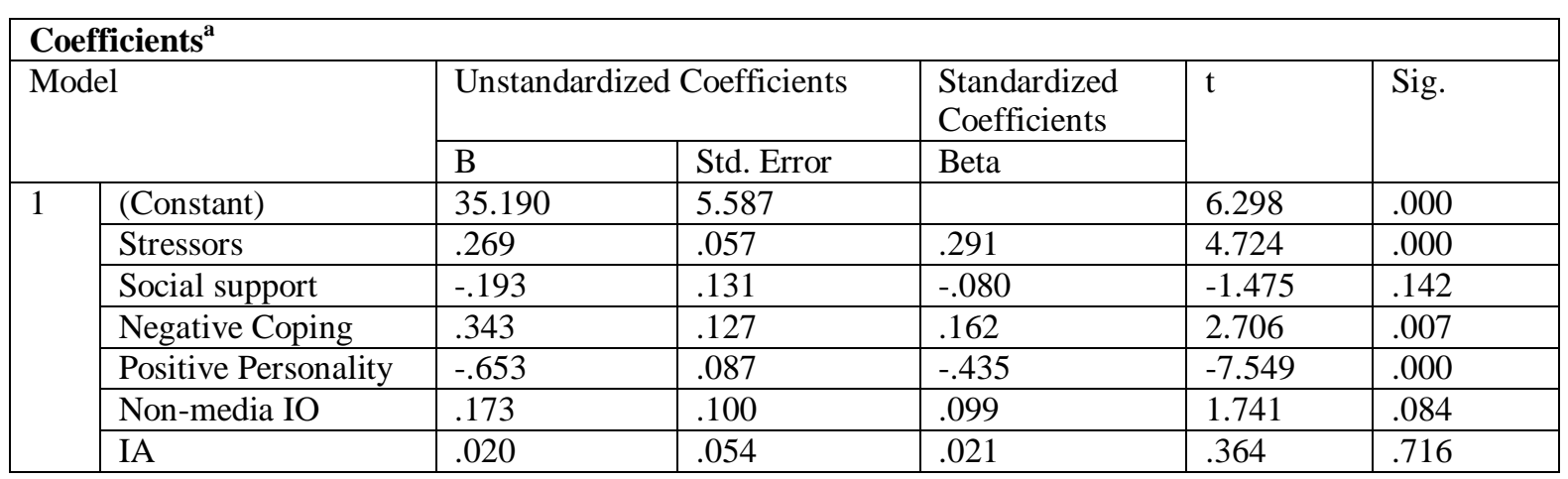

\subsection{Manova}

IA scores were splitto produce groups of controlled internet users and problematic internet users. There were no participants with IA scores in the category reflecting internet addiction. The two groups compared in the MANOVA were those with controlled use and those with problematic internet use.The dependent variables in the MANOVA were examination score, coursework score, negative wellbeing and positive wellbeing. Internet addiction did not have a significant effect (Wilks' Lambda $=0.98 p>0.05$ ), whereas stressors (Wilks' Lambda $=0.87 \mathrm{p}<0.001$ ), social support (Wilks' Lambda $=0.92 \mathrm{P}<0.05$ ) and positive personality (Wilks' Lambda $=0.55 \mathrm{p}<0.001$ ) did.

\section{DISCUSSION}

The present study showed that internet addiction scores were correlated with negative wellbeing and negatively associated with positive wellbeing. Numerically, internet addiction scores were negatively correlated with academic attainment but these effects were not statistically significant. This possibly reflects the sample size, the fact that few individuals had high IA scores, or the sample having only just started their university degree. Smith and Izadyar (2019) obtained similar results but the effects on academic attainment were significant. They had a larger sample $(\mathrm{N}>300)$ of students in their first and second year at university, and they measured hours of internet use and distraction from the internet.

The effects of IA on wellbeing were no longer significant when established predictors of wellbeing were covaried. This confirms the findings of Smith and Izadyar (2019) and supports the cognitive behavioural model of Davis $(2001,2002)$. Such results confirm the importance of controlling for the established predictors of wellbeing when assessing the effects of internet addiction. A limitation of the present study was that it used a cross-sectional design. A stronger method would have been to use a longitudinal design which gives a better indication of causality. Future research should also measure the type of internet use, using samples where it is more established (e.g. students from other cultures or workers).

In conclusion, the associations between internet addiction scores and wellbeing were found to reflect correlations between these factors and other aspects of the wellbeing process (e.g. positive personality, social support,exposure to stressors and negative coping). Numerically, internet addiction 
scores were associated with lower attainment scores but these effects were not significant. This suggests that such effects are small and a larger sample size is required to obtain significance.

\section{REFERENCES}

[1] Akin, A. (2012). The relationships between Internet addiction, subjective vitality, and subjective happiness. Cyberpsychology, Behavior, and Social Networking, 15, 404-410.doi:10.1089/cyber.2011 .0609

[2] Alavi, S. S., Maracy, M. R., Jannatifard, F. \& Eslami, M. (2011). The effect of psychiatric symptoms on the Internet addiction disorder in Isfahan's university students. Journal of Research in Medical Sciences, 16(6), 793-800.

[3] Alharbi E., \& Smith AP. (2019). Studying-away strategies: A three-wave longitudinal study of the wellbeing of international students in the United Kingdom. The European Educational Researcher, 2(1):59-77. https://doi.org/10.10.31757/euer.215

[4] Alheneidi, H. (2019). The influence of information overload and problematic Internet use on adults wellbeing. PhD Thesis, Cardiff University.

[5] Andreassen, C., Torsheim, T., Brunborg, G., \& Pallesen, S. (2012). Development of a facebook addiction scale. Psychological Reports, 110(2), 501-517.

[6] Beard, K. W. (2002). Internet addiction: Current status and implications for employees. Journal of Employment Counselling, 39(1), 2-11. doi:10.1002/j.2161-1920.2002.tb00503.x

[7] Bowen, L. \& Smith, A.P. (2019). Drive better, feel better: predicting well-being and driving behaviour in undergraduate psychology students. Advances in Social Science Research Journal, 6(2), 302-318. DoI:10.14738/assrj.62.6221.

[8] Caplan, S.E. (2002). Problematic Internet use and psychosocial well-being: development of a theory-based cognitive-behavioral measurement instrument. Computers in Human Behavior, 18(5), 553-575. doi: 10.1016/s0747-5632(02)00004-3

[9] Cardak, M. (2013). Psychological well-being and internet addiction among university students. The Turkish Online Journal of Educational Technology, 12(3), 134-141.

[10] Casale, S., Lecchi, S., \& Fioravanti, G. (2015). The association between psychological well-being and problematic use of Internet communicative services among young people. The Journal of Psychology: Interdisciplinary and Applied, 149, 480-497. doi:10.1080/00223980.2014.905432

[11] Chen, S. (2012). Internet use and psychological well-being among college students: A latent profile approach. Computers in Human Behavior, 28, 2219-2226. doi:10.1016/j.chb.2012.06.029

[12] Choi, S.B., \& Lim, M. (2016). Effects of social and technology overload on psychological well-being in young South Korean adults: The mediatory role of social network service addiction. Computers in Human Behavior, 61, 245-254. doi:10.1016/j.chb.2016.03.032

[13] Davis, R. (2001). A cognitive-behavioral model of pathological Internet use. Computers in Human Behavior, 17(2), 187-195. doi: 10.1016/s0747-5632(00)00041-8

[14] Davis, R. (2002). Psychological implications of technology in the workplace. Cyberpsychology \& Behavior, 5(4), 277-278. doi: 10.1089/109493102760275545

[15] Davis, R. A., Flett, G. L., \& Besser, A. (2002). Validation of a new scale for measuring problematic internet use: Implications for pre-employment Screening. Cyberpsychology \& Behavior, 5(4), 331-345. doi: $10.1089 / 109493102760275581$

[16] Ellison, N.B., Steinfeld, C., \& Lampe, C. (2007). The benefits of facebook "friends:" Social capital and college students' use of online social network sites. Journal of Computer-Mediated Communication, 12, 1143-1168. doi: 10.1111/j.1083-6101.2007.00367.x

[17] Eppler, M.J., \& Mengis, J. (2004). The concept of information overload: A review of literature from organization science, accounting, marketing, mis, and related disciplines. The Information Society, 20(5), 325-344.

[18] Fan J., \& Smith A.P. (2017a). Positive well-being and work-life balance among UK railway staff. Open Journal of Social Sciences, 5:1-6. https://doi.org/10.4236/jss.2017.56001

[19] Fan J., \& Smith A.P. (2017b). The impact of workload and fatigue on performance. In L. Longo \& M.C. Leva (Eds.), Human Mental Workload: Models and Applications. H-WORKLOAD 2017. Communications in Computer and Information Science. Cham: Springer. 726:90-105. https://doi.org/10.1 007/978-3-319-61061-0_6

[20] Fan J., \& Smith A.P. (2018). The mediating effect of fatigue on work-life balance and positive well-being in railway staff. Open Journal of Social Sciences. 6:1-10. https://doi.org/10.4236/jss.2018.66001 
[21] Galvin J. (2016). A multi-method approach to researching stress and mental health in two groups of healthcare students: Nursing students and trainee clinical psychologists. (PhD Thesis, Cardiff University, Cardiff). http://orca.cf.ac.uk/98616

[22] Gedam, S. R., Shivji, I. A., Goyal, A., Modi, L., \& Ghosh, S. (2016). Comparison of internet addiction, pattern and psychopathology between medical and dental students. Asian Journal of Psychiatry, 22, 105110. https://doi.org/10.1016/j.ajp.2016.06.007

[23] Greenfield, D. N., \& Davis, R. A. (2002). Lost in cyberspace: The web @ work. CyberPsychology \& Behavior, 5(4), 347-353.

[24] Hall, A.S., \& Parsons, J. (2001). Internet addiction: College student case study using best practice in cognitive behavior therapy. Journal of Mental Health Counselling, 23(4), 312-327.

[25] Hirao, K. (2015). Difference in mental state between Internet-addicted and non-addicted Japanese undergraduates. International Journal of Adolescent Medicine and Health, 27, 307-310. doi:10.1515/ijamh2014-0030

[26] Holmes, D. L. (Ed.). (1997). Virtual politics: Identity and community in cyberspace. London: Sage.

[27] Howells, K. \& Smith, A.P. (2019). Daytime sleepiness and the well-being and academic attainment of university students. OBM Neurobiology 3 (3) 1-18. doi:10.21926/obm.neurobiol.1903032

[28] Iacovelli, A., \& Valenti, S. (2009). Internet addiction's effect on likeability and rapport. Computers in Human Behavior, 25(2), 439-443. doi: 10.1016/j.chb.2008.10.006.

[29] Jones, Q., Gilad, R., \& Sheizaf, R. (2004). Information overload and the message dynamics of online interaction spaces: A theoretical model and empirical exploration. Information Systems Research, 15(2), 194-210.

[30] Kohn, A. (1990). The brighter side of human nature: Altruism and empathy in everyday life. New York: Basic Books.

[31] Kubey, R. W., Lavin, M. J., \& Barrows, J. R. (2001). Internet use and collegiate academic performance decrements: Early findings. Journal of Communication, 51(2), 366-382.

[32] Kutty, N., \& Sreeramareddy, C. (2014). A cross-sectional online survey of compulsive internet use and mental health of young adults in Malaysia. Journal of Family and Community Medicine, 21(1), 23-28. doi: $10.4103 / 2230-8229.128770$

[33] Kwon, M., Kim, D.J., Cho, H. \& Yang, S. (2013). The smartphone addiction scale: Development and validation of a short version for adolescents. PloS One, 8(12), e83558. 10.1371/journal.pone.0083558

[34] Laconi, S., Kaliszewska-Czeremska, K., Gnisci, A., Sergi, I., Barke, A., Jeromin,F., ...Kuss, D. (2018). Cross-cultural study of problematic Internet use in nine European countries. Computers in Human Behavior, 84, 430-440, https://doi.org/10.1016/j.chb.2018.03.020

[35] Lee, A. R., Son, S. M., \& Kim, K. K. (2016). Information and communication technology overload and social networking service fatigue: A stress perspective. Computers in Human Behavior, 55, 51-61.

[36] Marino, C., Vieno, A., Pastore, M., Albery, I. P., Frings, D. \& Spada, M.M. (2016). Modeling the contribution of personality, social identity and social norms to problematic Facebook use in adolescents. Addictive Behaviors, 63, 51-56. doi:10.1016/j.addbeh.2016.07.001

[37] Mark G.M. \& Smith AP. (2008). Stress models: A review and suggested new direction. In J. Houdmont \& S. Leka (Eds.), Occupational Health Psychology: European Perspectives on Research, Education and Practice. Nottingham: Nottingham University Press. pp. 111-144.

[38] Min-Pei, L. Huei-Chen, K., \& Jo Yung-Wei, W. (2011). Prevalence and psychosocial risk factors associated with internet addiction in a nationally representative sample of college students in Taiwan. Cyberpsychology, Behavior, and Social Networking, 14(12). http://doi.org/10.1089/cyber.2010.0574

[39] Misra, S., \& Stokols, D. (2011). Psychological and health outcomes of perceived information overload. Environment and Behavior, 44(6), 737-759. doi: 10.1177/0013916511404408

[40] Muusses, L. D., Finkenauer, C., Kerkhof, P., \& Billedo, C. J. (2014). A longitudinal study of the association between compulsive internet use and wellbeing. Computers in Human Behavior, 36, 21-28. doi:10.1016/j.chb.2014.03.035

[41] Naseri, L., Mohamadi, J., Sayehmiri, K., \& Azizpoor, Y. (2015). Perceived social support, self-esteem, and internet addiction among students of Al-Zahra University, Tehran, Iran. Iranian Journal of Psychiatry and Behavioral Sciences, 9(3), e421. doi: 10.17795/ijpbs-421

[42] Nelson, K. V., \& Smith, A. P. (2016). Occupational stress, coping and mental health in Jamaican police officers. Occupational Medicine, 66(6), 488-491.

[43] Nor N.I.Z., \& Smith A.P. (2019). Psychosocial characteristics, training attitudes and well-being of students: A longitudinal study. Journal of Education, Society and Behavioral Science, 29(1):1-26. https://doi.org/10.9734/ 
[44] Omosehin, O., \& Smith, A.P. (2019a). Adding new variables to the Well-being Process Questionnaire (WPQ) - Further studies of Workers and Students. Journal of Education, Society and Behavioral Science. 28(3): 1-19, Article no.JESBS.45535 ISSN: 2456-981X. DOI: 10.9734/JESBS/2018/45535

[45] Omosehin, O. \& Smith, A.P. (2019b). Nationality, Ethnicity and Well-being. Open Journal of Social Sciences, 7, 133-142, http://www.scirp.org/journal/jss ISSN Online: 2327-5960 ISSN Print: 2327-5952 https://doi.org/10.4236/jss.2019.75011

[46] Omosehin O., Smith A.P. 2019. Do Cultural Differences Play a Role in the Relationship Between Time Pressure, Workload and Student Well-Being?. In: Longo L., Leva M. (eds) Human Mental Workload: Models and Applications. H-WORKLOAD 2019. Communications in Computer and Information Science, vol 1107. Springer, Cham. DOI: https://doi.org/10.1007/978-3-030-32423-0_12 Print ISBN 978-3-03032422-3 Online ISBN 978-3-030-32423-0

[47] Petrie, H., \& Gunn, D. (1998). Internet" addiction": The effects of sex, age, depression, and introversion. Paper presented at the British Psychological Society Conference, London.

[48] Pratarelli, M. E., \& Browne, B. L. (2002). Confirmatory factor analysis of Internet use and addiction. CyberPsychology \& Behavior, 5(1), 53-64.

[49] Quinones, C., \& Kakabadse, N.K. (2015). Self-concept clarity, social support, and compulsive Internet use: A study of the US and the UAE. Computers in Human Behavior, 44, 347-356. doi:10.1016/j.chb.2014.11.019

[50] Scherer, K. (1997). College life online: Healthy and unhealthy Internet use. Journal of College Student Development, 38(6), 655-665.

[51] Senol-Durak, E., \& Durak, M. (2011). The mediator roles of life satisfaction and self-esteem between the affective components of psychological well-being and the cognitive symptoms of problematic internet use. Social Indicators Research, 103, 23-32. doi:10.1007/s11205-010-9694-4

[52] Shapira, N. A., Goldsmith, T. D., Keck, P. E., Khosla, U. M., \& McElroy, S. L. (2000). Psychiatric features of individuals with problematic internet use. Journal of Affective Disorders, 57, 267-272.

[53] Shapira, N. A., Lessig, M. C., Goldsmith, T. D., Szabo, S. T., Lazoritz, M., Gold, M. S., \& Stein, D. J. (2003). Problematic Internet use: Proposed classification and diagnostic criteria. Depression and Anxiety, 17, 207-216.

[54] Skues, J., Williams, B., Oldmeadow, J., \& Wise, L. (2016). The effects of boredom, loneliness, and distress tolerance on problem internet use among university students. International Journal of Mental Health and Addiction, 14(2), 167-180.

[55] Smith, A.P. (2018). Cognitive fatigue and the well-being and academic attainment of university students. Journal of Education, Society and Behavioral Science, 24(2), 1-12. DOI: 10.9734/JESBS/2018/39529

[56] Smith, A.P. 2019. Student Workload, Wellbeing and Academic Attainment. In L. Longo and M.C. Leva (eds) H-WORKLOAD 2019. Communications in Computer and Information Science 1107. (C) Springer Nature Switzerland AG. https://doi.org/10.1007/978-3-030-32423-0_3 Print ISBN 978-3-030-32422-3. Online ISBN 978-3-030-32423-0

[57] Smith, A.P. \& Firman, K.L. (2019). Associations between the wellbeing process and academic outcomes. Journal of Education, Society and Behavioural Science, 32(4), 1-10.. Article number: JESBS 53119. ISSN: 2456-981X. DOI:10.9734/JESBS/2019/v32i430185

[58] Smith, A.P. \& Firman, K.L. (2020). The microstructure of the student wellbeing process questionnaire. Journal of Education, Society and Behavioural Science, 33 (1), 76-83. Article no: m55068. ISSN: 2456981X https://doi.org/10.9734/jesbs/2020/v33i130196

[59] Smith, A.P. \& Izadyar, S. (2020). Effects of the internet, other media and study time on wellbeing and academic attainment of university students. International Journal of Education Humanities and Social Science, Vol. 3, No. 02, 1-13, ISSN: 2582-0745. http://ijehss.com/view2.php?issue=2

[60] Smith A.P. \& Smith H.N. (2017a). An international survey of the wellbeing of employees in the business process outsourcing industry. Psychology, 8(1):160-167. https://doi.org/10.4236/psych.2017.81010

[61] Smith A.P. \& Smith H.N. (2017b). Workload, fatigue and performance in the rail industry. In L. Longo \& M. C. Leva (Eds.), Human Mental Workload: Models and Applications. H-WORKLOAD. 2017. Communications in Computer and Information Science. Cham: Springer. 726, 251-263. https://doi.org/10.1007/978-3-319-61061-0_17

[62] Smith A.P. \& Smith H.N. (2017c). A short questionnaire to measure wellbeing at work (Short-SWELL) and to examine the interaction between the employee and organisation. In R. Charles \& J. Wilkinson (Eds.), Contemporary Ergonomics and Human Factors 2017 Chartered Institute of Ergonomics and Human Factors. Pp. 200-205.

[63] Smith A.P., Wadsworth, E.J.K., Chaplin, K., Allen, P.H. \& Mark G. (2011). The relationship between work/well-being and improved health and well-being. Leicester: IOSH. 
[64] Soto-Acosta, P., Molina-Castillo, F. J., Lopez-Nicolas, C., \& Colomo-Palacios, R. (2014). The effect of information overload and disorganisation on intention to purchase online: The role of perceived risk and internet experience. Online Information Review, 38(4), 543-561. https://doi.org/10.1108/OIR-01-20140008

[65] Tang, J., Chen, M., Yang, C., Chung, T., \& Lee, Y. (2016). Personality traits, interpersonal relationships, online social support, and Facebook addiction. Telematics and Informatics, 33(1), 102-108. doi: 10.1016/j.tele.2015.06.003

[66] Tsai, H. F., Cheng, S. H., Yeh, T. L., Shih, C. C., Chen, K. C., \& Yang, Y. C. (2009). The risk factors of Internet addiction - A survey of university freshmen. Psychiatry Research, 167(3), 294-299. doi: 10.1016/j.psychres.2008.01.015

[67] Valenzuela, S., Park, N., \& Kee, K. F. (2009). Is there social capital in a social network site? Facebook use and college students' life satisfaction, trust, and participation. Journal of Computer-Mediated Communication, 14, 875-901. doi: 10.1111/j.1083-6101.2009.01474.x

[68] Wadsworth, E.J.K., Chaplin, K., Allen, P.H., Smith, A.P. (2010). What is a Good Job? Current Perspectives on Work and Improved Health and Well-being. The Open Health \& Safety Journal, 2:9-15. https://doi.org/10.2174/1876216601002010009

[69] Whang, L. S., Lee, S., \& Chang, G. (2003). Internet over-users' psychological profiles: A behavior sampling analysis on Internet addiction. CyberPsychology \& Behavior, 6(2), 143-150.

[70] Williams, G. (2014). Researching and developing mental health and well-being assessment tools for supporting employers and employees in Wales (Doctoral dissertation). Cardiff University, Wales.

[71] Williams, G., Pendlebury, H., \& Smith, A.P. (2017) Stress and well-being of nurses: an investigation using the demands-resources- individual effects (DRIVE) model and well-being process questionnaire (WPQ). Jacobs Journal of Depression and Anxiety, 1,1-8.

[72] Williams, G., Pendlebury, H., Thomas, K., \& Smith, A.P. (2017). The student wellbeing process questionnaire (Student WPQ). Psychology, 8, 1748-1761 http://doi.org/10.4236/psych.2017.811115

[73] Williams, G., \& Smith, A. P. (2012). A holistic approach to stress and well-being. Part 6: The wellbeing process questionnaire (WPQ Short Form). Occupational Health [At Work], 9(1), 29-31.

[74] Williams, G., \& Smith, A.P. (2013). Measuring wellbeing in the workplace: Single item scales of depression and anxiety. In M. Anderson (Ed.), Contemporary ergonomics and human factors 2013 (pp. 87 94). Boca Raton, FL: CRC Press.

[75] Williams, G., \& Smith, A.P. (2016). Using single-item measures to examine the relationships between work, personality, and well-being in the workplace. Psychology: Special Edition on Positive Psychology, 7(6), 753-767. doi: 10.4236/psych.2016.76078

[76] Williams, G., \& Smith, A.P. (2018). A longitudinal study of the well-being of students using the student well-being questionnaire (WPQ). Journal of Education, Society and Behavioral Science, 24(4), 1-6. doi: 10.9734/JESBS/2018/40105

[77] Williams, G., \& Smith, A.P. (2018). A practical method of predicting wellbeing at work: The wellbeing process tool. Advances in Social Sciences Research Journal, 5(2), 86-93. doi: 10.14738/assrj.52.4158

[78] Williams, G., \& Smith, A.P. (2018). Diagnostic validity of the anxiety and depression questions from the well-being process questionnaire. Journal of Clinical and Translational Research, 4(2), 101-104. doi: 10.18053/jctres.04.201802.001

[79] Williams, G., Thomas, K., \& Smith, A.P. (2017) Stress and well-being of university staff: an investigation using the demands-resources- individual effects (DRIVE) model and well-being process questionnaire (WPQ). Psychology, 8, 1919-1940. https://doi.org/10.4236/psych.2017.812124

[80] Yan, W., Li, Y., \& Sui, N. (2014). The relationship between recent stressful life events, personality traits, perceived family functioning and Internet addiction among college students. Stress and Health: Journal of the International Society for the Investigation of Stress, 30(1), 3-11. doi:10.1002/smi.2490

[81] Young, K.S. (1996). Psychology of computer use: XL. Addictive use of the Internet: a case that breaks the stereotype. Psychological Reports, 79(3), 899-902.

[82] Young, K.S. (1998). Internet addiction: The emergence of a new clinical disorder. Cyberpsychology \& Behavior, 1(3), 237-244. http://dx.doi.org/10.1089/cpb.1998.1.237

\section{AUTHORS' BIOGRAPHY}

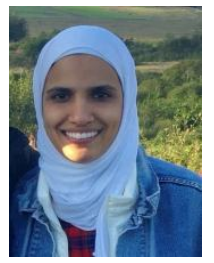

Dr Hasah AlHeneidi, Psychological researcher at the Social Development Office, Kuwait. PhD holder in Occupational and Health Psychology from Cardiff University, UK. Hasah has an interest in studying wellbeing and technology related topics. 


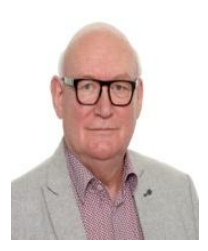

Andy Smith, is Professor of Psychology and Director, Centre for Occupational and Health Psychology, Cardiff University. He completed his undergraduate and postgraduate degrees at University College London. Following this he was a post-doctoral fellow at Oxford University, conducting research with Donald Broadbent on the effects of noise. This was followed by a job at the MRC Perceptual and Cognitive Performance Unit, Sussex University, where he carried out research on effects of working hours, nutrition and behaviour, and the effect of minor illnesses on performance efficiency. In 1990 he moved to Cardiff University and then became Professor of Psychology at the University of Bristol in 1993. He returned to Cardiff in 1999. He has published over 500 papers and given over 200 invited talks and conference papers.

Citation: Hasah Alheneidi, PhD, Andrew P Smith, PhD. "Effects of the Internet use on Wellbeing and Academic Attainment of Students Starting University" International Journal of Humanities Social Sciences and Education (IJHSSE), vol 7, no. 5, 2020, pp. 20-34. doi: http://dx.doi.org/10.20431/2349-0381.0705003.

Copyright: () 2020 Authors. This is an open-access article distributed under the terms of the Creative Commons Attribution License, which permits unrestricted use, distribution, and reproduction in any medium, provided the original author and source are credited. 